\title{
Levothyroxine Absorption Test in the management of a patient with persistent hypothyroidism
}

\author{
Joana André Monteiro, Marta Ferreira, Miguel Pires, Célio Fernandes \\ Centro Hospitalar de Leiria
}

\section{Introduction}

Hypothyroidism refers to the common pathological condition of thyroid hormone deficiency. If untreated, it can lead to serious adverse health effects and ultimately death ${ }^{1}$. Synthetic thyroxine has been used to treat hypothyroidism successfully since $1927^{2}$. The optimal daily dose of 1.6$1.8 \mathrm{ug} / \mathrm{body}$ weight $(\mathrm{kg})$ per day of levothyroxine (LT4) is an appropriate replacement dose ${ }^{1-3}$. The absorption of oral LT4 occurs mostly in the jejunum and ileum (60-80\% of the ingested dose) $)^{3-6}$. It is maximal when the stomach is empty and takes place within the first 3 hours of ingestion?

For patients who require larger doses of LT4 than expected, the underlying cause can be challenging to determine ${ }^{2}$. Several factors must be considered: low patient compliance, reduced LT4 absorption from interfering dietary factors and medications, or gastrointestinal disorders contributing to malabsorption?

The most common cause of mal-absorption is poor or non-compliance with oral LT4 treatment by the patient ${ }^{8}$. Compliance with treatment is the key to good outcomes in medical care. Medical non-compliance is a major public health problem that imposes a considerable financial burden upon modern healthcare systems and is also a source of ongoing frustration to doctors ${ }^{9}$.

The concept of pseudo-malabsorption of thyroid hormones was first outlined in 1991 when it was described a factitious disorder due to patient non-compliance with the intention to deceive ${ }^{10}$. An effective way to distinguish nonadherence from mal-absorption is to perform levothyroxine absorption testing $(\mathrm{LAT})^{5}$.

This article aims describe the LT4 absorption rapid test in a patient with hypothyroidism, highlighting its importance in the diagnosis of LT4 pseudo-malabsorption.

Keywords: Hypothyroidism. Levothyroxine. Pseudomalabsportion. Levothyroxine Absorption Test.

Palabras clave: Hipotiroidismo. Levotiroxina. Pseudomalabsorciónm. Test de absorción de levotiroxina.

\section{Case report}

A 60-year-old woman with Graves' hyperthyroidism was treated with radioactive iodine $(9 \mathrm{mCi})$ at the age of 47 . She subsequently developed hypothyroidism and was prescribed on LT4. Ever since, she has needed increasing doses of oral LT4, without reaching a euthyroid state.

The issue of nonadherence to treatment was raised several times over the years, but the patient reported to her doctor that she was consistently taking her medications. Her levothyroxine dosage was gradually increased to $1000 \mu \mathrm{g}$ daily in an attempt to achieve a serum thyroid-stimulating hormone (TSH) level within the normal range. Despite oral treatment with large doses of T4 TSH had persistently remained elevated between 13,70 and 38,91 $\mu \mathrm{Ul} /$ $\mathrm{mL}$ (reference range: 0,38 to 5,33 ). Although the different doses prescribed, there was no apparent relation with the variation in TSH levels. (Fig 1.)

The patient was also being treated for diabetes mellitus and dyslipidaemia. She was on LT4, metformin, sitagliptin, nateglinid and simvastatin. Her only complaint was hair loss and her physical examination was normal. Anamnesis excluded drug and dietary interference, and also previous gastrointestinal surgery.

The patient had no clinical signs of malabsorption. Gastrointestinal, liver or pancreas diseases were excluded through laboratory investigations. Congestive heart failure and pregnancy were not present either. She had no other concomitant medication that could interfere with levothyroxine absorption or metabolism.

After careful consideration, with the patient's consent, it was decided to conduct a LAT: she was advised to miss her breakfast and the test was performed with very close clinical monitoring.
After baseline blood sampling for thyroid function testing [TSH, free thyroxine (FT4) and free triiodothyronine (FT3)], 1000 $\mu \mathrm{g}$ of levothyroxine was administrated orally in a fasting state at 8 a.m. - 10 pills of 100ug - each tablet was taken separately, with an adequate amount of water and under close supervision. Repeated blood sampling for thyroid function tests, blood pressure and heart rate were taken at $0,60,120,180$ e 240 minutes after administration. The results are presented in the table below.

Table 1. LAT results: TSH ( $\mu \mathrm{Ul} / \mathrm{mL})$, FT4 (pmol/L) and FT3 (pmol/L) levels, heart rate rpm (HR), blood pressure $\mathrm{mmHg}(\mathrm{BP})$ on $0,60,120,180$ and 240 minutes.

\begin{tabular}{|c|c|c|c|c|c|}
\hline minutes & TSH & FT4 & FT3 & HR & BP \\
\hline 0 & 34,02 & 2,1 & 2,30 & $146 / 77$ & 56 \\
\hline 60 & 30,76 & 10,7 & 2,30 & $150 / 84$ & 54 \\
\hline 120 & 28,44 & 16,9 & 2,60 & $148 / 82$ & 55 \\
\hline 180 & 27,39 & 16,1 & 3,20 & $135 / 80$ & 50 \\
\hline 240 & 26,08 & 19,9 & 2,70 & $121 / 69$ & 62 \\
\hline
\end{tabular}

The serum FT4 level increased from 2,1 pmol/L to $19,9 \mathrm{pmol} / \mathrm{L}$ and the serum TSH level declined from $34 \mu \mathrm{Ul} / \mathrm{mL}$ to $26 \mu \mathrm{UI} / \mathrm{mL}$ within 4 hours after administration of LT4. Serum FT3 level also increased from 2,3 pmol/L to 2,7 pmol/L. Heart rate and blood pressure remain stable. 
Figure 1. TSH level and LT4 daily doses through the years.

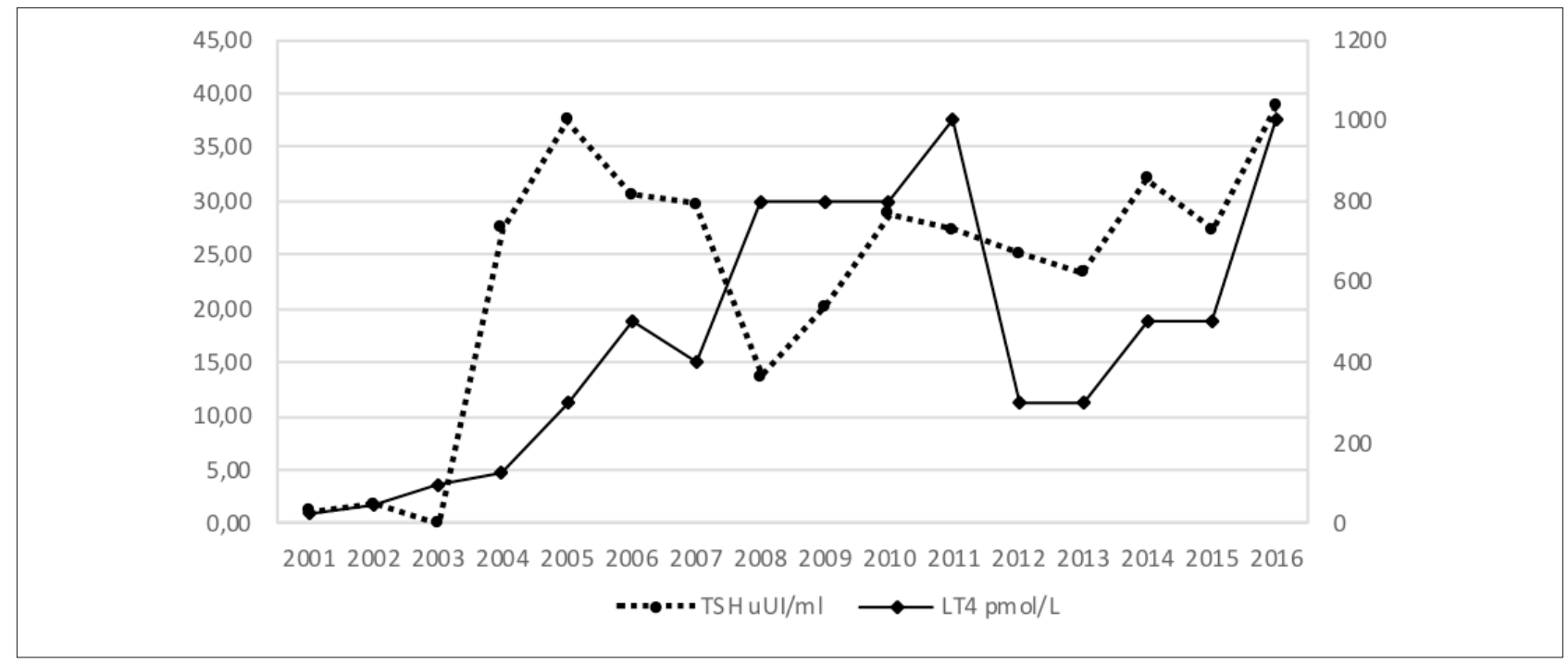

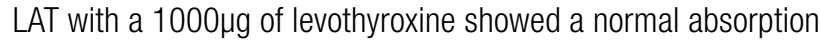
of LT4 indicating that malabsorption was not the likely cause of resistant hypothyroidism in our patient.

This test proved poor adherence to treatment or pseudo-malabsorption.

\section{Discussion}

The daily use of oral LT4 is the most frequent treatment of hypothyroidism and is one of the most effective, inexpensive and safe hormone replacements in endocrinology. Although in some patients hypothyroidism persists despite therapy with high doses of levothyroxine ${ }^{4}$.

In patients with persistently elevated TSH levels, there are a number of causes, which needs to be considered, including poor administration and pathological malabsorption conditions. However, the literature is not clear on the actual degree of malabsorption, in each malabsorptive condition ${ }^{11}$.In the majority of the cases, the combination of history and examination identifies biological causes of LT4 malabsorption. Therefore, before more detailed investigations, the issue of adherence needs to be addressed².
Ain et al. ${ }^{12}$ introduced the term of pseudo-malabsorption after evaluating four cases of persistent hypothyroidism despite high oral doses of thyroid replacement therapy the main characteristic of thyroxine pseudo-malabsorption is patient's denial of poor compliance, which leads to difficulties in diagnosis and management.

The LAT is the primary method for distinguishing between non-compliance and true malabsorption. However, the performance of the test is non-uniform with the existence of various protocols in the literature but with no clarity on which one method is the most efficacious, sensitive and specific. The majority advocate a same-day dosage (1000$2000 \mathrm{mcg}$ ) of LT4 orally and then measuring TSH and FT4 levels at 2 and possibly 4 and 6 hours, demonstrating a rise in FT4 and a fall in the TSH. An increase in FT4 is observed with a maximum level within the first 120min, known to be a normal time interval for absorption in the jejunum and ileum ${ }^{4}$. If the biochemical markers rise as expected, then this is indicative of normal gastrointestinal absorption for levothyroxine.

Figure 2. Evolution of LT4 and TSH levels in LAT.

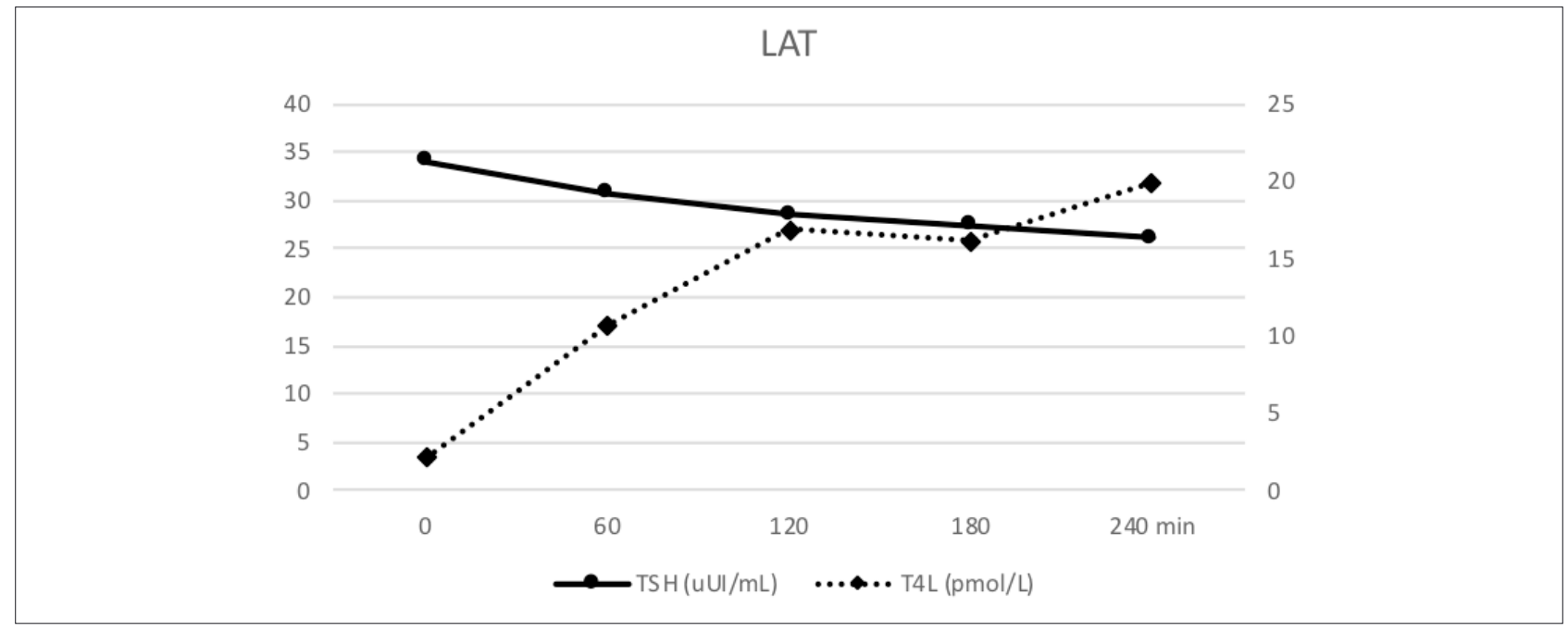


The side effects of a single high oral dose of levothyroxine are limited. None of the previously published cases presented with adverse events following ingestion. That is partially explained by the fact that T4 is tightly bound by circulating thyroxine-binding globulin and enters the tissues very slowly; also, T4 must be converted in T3 in order to be biologically active $^{10}$. This process is highly regulated and the increasing of FT4 is not followed by a significant rise in $\mathrm{FT}^{13}$. Our patient tolerated the oral test with $1000 \mu \mathrm{g}$ of oral levothyroxine very well. A rise in serum FT4 was observed after ingestion associated with a decrease in TSH and without a significant rise in $\mathrm{FT} 3$.

After pseudo-malabsorption is identified, several strategies can be adopted to improve treatment outcomes for the future based on a closer understanding of the patients' perspectives of their illness, lifestyle and health beliefs, rather than the perceptions and expectations of healthcare professionals. The improvement of doctor-patient relationship is very important ${ }^{2}$. To improve the state of hypothyroidism two main prescriptions are possible: supervised weekly thyroxine replacement (the total weekly dose of LT4 given once per week) or parenteral administration (intramuscular or intravenous) of levothyroxine ${ }^{3,14}$.

Once weekly administration of LT4 is safe and efficient and therefore a possible alternative to customary daily therapy. It is well tolerated, and there is no evidence of possible toxicity, including cardiac side effects - our patient didn't raise her heart rate or her blood pressure during the test ${ }^{4,15}$.

This patient was therefore prescribed on one dose of LT4 weekly. The FT4 and TSH serum levels normalized and the patient continued to do well during follow-up.

In conclusion, pseudo-malabsorption is an important differential diagnosis in persistent hypothyroidism. It's very important to be excluded to achieve therapeutic success. Levothyroxine absorption test is a simple, safe and useful tool in these cases.

\section{References}

1. Chaker L, Bianco AC, Jonklaas J, Peeters RP. Hypothyroidism. Lancet (London, England) [Internet]. 2017 [cited 2017 Nov 13];390(10101):1550-62. Available from: http://www.ncbi.nlm.nih.gov/pubmed/28336049.

2. Walker JN, Shillo P, Ibbotson V, Vincent A, Karavitaki N, Weetman AP, et al. A thyroxine absorption test followed by weekly thyroxine administration: A method to assess non-adherence to treatment. Eur J Endocrinol. 2013;168(6):913-7.

3. Kempke J, Hussain H, Bhan B, Graves L. Treatment of Thyroxine Malabsorption. J Endocrinol Metab. 2015;5(1-2):192-5.

4. Van Wilder N, Bravenboer B, Herremans S, Vanderbruggen N, Velkeniers B. Pseudomalabsorption of Levothyroxine: A Challenge for the Endocrinologist in the Treatment of Hypothyroidism. Eur Thyroid J [Internet]. 2017;6(1):52-6. Available from: https://www.karger.com/?doi=10.1159/000452489.

5. Balla M, Jhingan RM, Rubin DJ. Rapid levothyroxine absorption testing: A case series of nonadherent patients. Int J Endocrinol Metab. 2015;13(4):13-6.

6. Srinivas V, Oyibo SO. Levothyroxine pseudomalabsorption and thyroxine absorption testing with use of high-dose levothyroxine: case report and discussion. Endocr Pract [Internet]. 2010 Nov;16(6):1012-5. Available from: http://www.ncbi.nlm.nih. gov/pubmed/21041167.

7. Kempke J, Hussain H, Bhan B, Graves L. Treatment of Thyroxine Malabsorption. J Endocrinol Metab. 2015;5(1-2):192-5

8. Lips DJ, van Reisen MT, Voigt V, Venekamp W. Diagnosis and treatment of levothyroxine pseudomalabsorption. Neth J Med [Internet]. 2004 Apr;62(4):114-8. Available from: http://www.ncbi.nlm.nih.gov/pubmed/15255080.

9. Vermeire, E., Hearnshaw, H., Van Royen, P. and Denekens J, Vermeire E, Hearnshaw $H$, Van Royen P, Denekens J. Patient adherence to treatment: three decades of research. A comprehensive review. J Clin Pharm Ther [Internet]. 2001;26(5):331-42. Available from: http://doi.wiley.com/10.1046/j.1365-2710.2001.00363.

10. Livadariu E, Valdes-Socin H, Burlacu M-C, Vulpoi C, Daly A-F, Beckers A. Pseudomalabsorption of thyroid hormones: case report and review of the literature. Ann Endocrinol (Paris) [Internet]. 2007 Dec;68(6):460-3. Available from: http://linkinghub. elsevier.com/retrieve/pii/S0003426607002582.

11. Butt MI, Gupta N, Tan HL, Waheed N. Clinical Application of the Levothyroxine Absorption Test in the Diagnosis of Pseudo-Malabsorption. 2014;2(11):253-5.

12. Ain KB. Pseudomalabsorption of Levothyroxine. JAMA J Am Med Assoc [Internet]. 1991 Oct 16;266(15):2118. Available from: http://www.ncbi.nlm.nih.gov/pubmed/1920700.

13. Li H, Yuan X, Liu L, Zhou J, Li C, Yang P, et al. Clinical Evaluation of Various Thyroid Hormones on Thyroid Function. Int J Endocrinol [Internet]. 2014;2014:1-5. Available from: http://www.hindawi.com/journals/ije/2014/618572/.

14. Ramadhan A, Tamilia M. Treatment-refractory hypothyroidism. Can Med Assoc J [Internet]. 2012 Feb 7;184(2):205-9. Available from: http://www.cmaj.ca/cgi/ doi/10.1503/cmaj.110994.

15. Marques R, Soares V, Marinho De Figueiredo R, Melo M, Dantas N, Virgínia M, et al. Rapid Levothyroxine (Lt4) Absorption Test for Diagnosis of Lt4 Pseudomalabsorption: Case Report and Proposal of a Cutoff Point. J Endocrinol Diabetes Obes [Internet]. 2016;4(1). Available from: https://www.jscimedcentral.com/Endocrinology/endocrinology-4-1083.pdf. 